\title{
Emergency preparedness in integrated management systems: case study of the Port of Tallinn
}

\author{
A. Tammepuu ${ }^{1}$, O. Tammepuu ${ }^{2} \&$ K. Sepp ${ }^{1}$ \\ ${ }^{1}$ Estonian University of Life Sciences, Estonia \\ ${ }^{2}$ Tondi Tulekaitse Ö̈, Estonia
}

\begin{abstract}
The paper discusses the problem of the integration of emergency preparedness and safety management into the ISO-based integrated management system (IMS). The international and national legal requirements for ports embrace different aspects of safety, but unfortunately do not give an entire conception of safety management. The standard ISO 14001 requires procedures for emergency preparedness from the organisations which have implemented it, but at the same time, emergency is not strictly defined in the standard and the formulation of the requirements' permit various interpretations. Thereof, our goal was to analyse the existing situation in the port of Tallinn and develop an updated conceptual approach during the improvement process of the integrated management system, suitable for the specific port and maybe partly applicable in other similar organisations.

The problem was observed in the context of a case study of the Port of Tallinn, which has implemented the integrated quality and environmental management system. The work, presented in this paper, was carried out in the frames of the Interreg IIIB programme DaGoB "Safe and Reliable Transport Chains of Dangerous Goods in the Baltic Sea Region". The first step was the analysis of the management system, bringing out the gaps and ambiguities, concerning emergency preparedness and safety management. The second step was working out solutions and proposal; the third step, the compilation of a relevant thematic handbook, in addition to a general handbook of the IMS.
\end{abstract}

Keywords: emergency preparedness and response, risk assessment, public safety. 


\section{Introduction}

During the history of mankind, human beings have always been exposed to different hazards. Emergencies have occurred in the past, occur nowadays and will occur in the future. Or in other words: accidents will happen again - it is only a question of time [1]. Therefore, the approaches for avoiding accidents, and creating a safer environment and society, have a long history. Currently the requirements concerning emergency preparedness and response can be found in several international/national legal documents and also in various standards. At the same time the meaning of emergencies differ remarkably in different issues.

The ISO 14001 for Environmental Management Systems is one of the standards containing direct requirements for emergency preparedness and response. [2] Since 1996 more than 87,000 organizations in 128 countries have been certified observing the ISO 14001 Environmental Management System standard [3]. Emergency preparedness and response is one of the key elements of the standard, which is closely connected with other elements. In Estonia today, there are over 270 enterprises certified observing the ISO 14001 standard [4]. All these organisations have taken responsibility for the subject of emergency preparedness and response.

The Port of Tallinn is one of the Estonian ISO 14001 certified enterprises. The Port of Tallinn has implemented an integrated (quality and environmental) management system (IMS), responding on both: ISO 9001 and ISO 14001 [5]. The port has 5 different harbours on different sites, 3 of which are situated in Tallinn or in close proximity. Dangerous goods (DG) in large quantities are handled in four of the five ports. A number of enterprises with major chemical accident hazard are situated directly on the territories of the harbours. These enterprises have their own safety management systems. In spite of different hazardous activities taking place on the territories and aquatic areas of the harbours, the port has only limited legal responsibility, concerning emergency preparedness and response. At the same time the organisation is voluntarily taking more duties in this field due to the implementation of ISO 14001 standards (together with ISO 9001). Currently environmental protection in companies is increasingly conducted using IMS [6].

The essential goals of our study were first analyse the existing situation in the Port of Tallinn, bringing out the gaps and ambiguities, addressing emergency preparedness and safety management. Secondly, to develop an updated conceptual approach during the improvement process of the integrated management system, containing relevant solutions and proposals. The final outcome was the compilation of a handbook of emergency preparedness and response for the Port of Tallinn on the basis of the study, as an additional manual to the handbook of IMS, facilitating both routine activities and continual improvement. The research materials used were existing documents, outcomes from interviews with key people and results of the observations. The work was carried out in the frames of the Interreg IIIB programme DaGoB "Safe and Reliable Transport Chains of Dangerous Goods in the Baltic Sea Region" [7]. Although the programme was directed mainly to dangerous goods, our study 
observed a broader circle of risks of the emergencies in the context of IMS of the port.

\section{Emergency preparedness in ISO 14001}

The ISO 14001 standard provides a practical and workable framework for controlling environmental risk to prevent accidents and environmental regulation violations [8]. Emergency preparedness is one of the key elements of ISO 14001 [2]. The avoidance of environmental risks arising from the activities of the organisation and mitigation of the impact deriving from accidents and emergencies is one of the goals of implementing the environmental management system (EMS) [9]. The organizations voluntarily follow set standards to establish, implement and maintain procedures to identify potential emergency situations as well as potential accidents and respond to them. These organizations are also compelled to respond to actual emergency situations and accidents while preventing or mitigating associated adverse environmental impacts.

At the same time the meanings of emergency or emergency preparedness are not defined in the ISO 14001. Certain ambiguities may cause different understandings of the standard requirements. The Estonian Emergency Preparedness Act [10], for example, designates an emergency as an event or a chain of events which endangers national security, the life and health of persons, significant damages to the environment, or causes extensive economic damage. Responding to any of these requires the co-ordinated action of the Government of the Republic, government agencies and local governments. It is obvious that this definition, although being the legal one in Estonia, does not fit into the context of the ISO 14001, as it is almost equivalent with Smith's [11] definition of disaster. This is the following: an event, concentrated in time and space, in which a community experiences severe danger and disruption of its essential functions, accompanied by widespread human, material, or environmental losses, which often exceed the ability of the community to cope without external assistance.

The EU Civil Protection Financial Instrument [12] defines emergency as any situation which has or may have an adverse impact on people and their preparedness as a state of readiness which the capacity of human and material means enable them to ensure. This definition permits the observation of almost any kind of accident, where human beings suffer (even slightly), as an emergency. Martin [13] brings out that emergencies include releases of all types to the environment, whereby natural disasters that might lead to releases, and process hazards that might become emergencies. In our opinion an emergency, in the context of the environmental management system (as well as IMS), can be principally defined as an accident where outside aid is additionally required for adequate response. For organizations or enterprises of different sizes, emergencies are accidents for which rescue, ambulance, police etc. are called for.

Although the ISO 14001 does not define or include the word 'risk', the identification of potential emergency situations and accidents is actually the 
assessment of the risk of emergency situations and accidents. In spite of the absence of the term 'risk' in the standard(s), different sources within the ISO 14001 contemplate risk assessment and management. Besides, risk in the different issues of ISO 14001 [14-16] is observed in a broader context than that of the merely emergencies and accidents, covering additional uncertain and undesirable environmental impacts.

Usually an accountable part of hazards the organisation is faced with are onsite hazards being (or connected with) environmental aspects. The potential accidents and emergency situations arising from these have to be observed during the assessment of environmental aspects as the impacts of such aspects. The ISO 14001 sets [17] that environmental aspects should not be limited only to normal operational conditions; abnormal and emergency situations must also be considered. This presumes that the selected methodology for environmental aspect assessment is obliged to take into account probability (e.g. assess the risk). Voorhees and Woellner [16] point out, that for understanding the degree of risk, ISO 14001 requires the following environmental concerns need to be addressed: the scale of the impact, the severity of the impact, the probability of occurrence, and the duration of impact. Organizations, in addition to first-string, often engage risk management specialists to assist in the identification of potential emergency or accident situations that could lead to human injury, environmental damage, or economic loss [18].

The ISO 14001 does not specify that the accidents and emergency situations, covered by the procedure(s), descend only from the elements of an organisation's activities, products and services, (e.g. environmental aspects - on-site hazards). Conversely, the responding guidance of ISO 14004 [19] mentions that in establishing its procedure(s), the organization should include consideration of the potential for (an) emergency situation(s) or accident(s) at a nearby facility (e.g. plant, road, railway line). Therefore, the organisation has to broaden the circle of potential emergency situations. Hence the coordination of additional risk assessment(s) or the analyse of the outcomes of out-site risk assessments are necessary for the complete identification of the potentially hazardous events.

The ISO 14001 only requires the existence of the procedure(s), covering inter alia the response to accidents and emergencies. The laconic and unspecified formulation in the standard enables various viewpoints and interpretations. A number of authors [9, 16, 20,21] recommend the compilation of emergency plan(s) in addition to or emanating from the procedure(s). Batts [20] points out, that large companies usually have such plans already implemented at all sites. Voorhees and Woellner [16] make the point that, according to ISO 14004 recommendations, emergency plans can document emergency organization and responsibilities; a list of key personnel; details of emergency services; internal and external communication plans; actions taken in the event of different types of emergencies; information on hazardous materials, such as material safety datasheets; and training plans and testing for effectiveness. Belmane et al [9] (in addition to previous) mention the overview of special resources and equipment and guidelines for handling the accident residue. 
An important requirement of the ISO 14001 concerns the periodic testing and simulation of emergency procedures, but leaves open the ways and frequency of such testing, which can lead to disagreements between auditors and clients [20]. Belmane et al [9] express that the absence of such periodical testing has appeared as a typical mistake in the maintenance of the EMS.

\section{Case study of the Port of Tallinn}

\subsection{Brief overview of the port of Tallinn}

The Port of Tallinn is the largest port in Estonia and, as far as both cargo and passenger traffic are taken into account, the biggest port on the Baltic Sea [22]. The Port of Tallinn is a state-owned company that unites five ports: Muuga Harbour, Old City Harbour, Paljassaare Harbour, Paldiski South Harbour, and Saaremaa Harbour. The organisation's main activities are ship traffic and port infrastructure management. Today, Port of Tallinn operates as a landlord type of port with no cargo handling operations of its own. Cargo handling and passenger transport are managed by the port operators, who are wholly responsible for the safe operation of the ports.

Aimed at improving customer satisfaction and effectiveness of environmental actions, Port of Tallinn has utilized, since 2003, an integrated quality and environmental management system which meets the requirement of the international standards ISO 9001:2000 and ISO 14001:2004 [23]. The safety management of the Port of Tallinn has been integrated with the quality and environmental management system for effective prevention of, and operative response to, hazards. All port facilities also have security plans approved by the national maritime authority and are compliant with ISPS requirements.

Subsequently the five harbours are briefly exemplified. All harbours are navigable all the year round and easily approachable with depths of up to 18 meters enabling them to receive all vessels able to pass the Danish Straits. Taking into account that the DaGoB project, in the frames of which this study was conducted, had orientation on dangerous goods (DG), additional attention is turned to this topic, characterizing the five ports. There are numerous risks related to the transportation of dangerous goods, including risk to human health and safety, risk to environment, risk to property and other types of risk [24]. Large volumes of hazardous cargo, mediated by the operators, are passing through the ports. Thus, serious accidents during their handling may endanger the employees of the Port of Tallinn and the normal operation of the ports.

Muuga Harbour is the biggest cargo harbour in Estonia and specializes in handling transit origin goods. It is the main cargo harbour for Port of Tallinn and is located approximately $17 \mathrm{~km}$ east of Tallinn. The port area covers territories of three different municipalities. The cargo volume handled at Muuga accounts for around $80 \%$ of the total cargo volume of Port of Tallinn and approximately $90 \%$ of all the transit cargo volume passing through Estonia. Nearly $75 \%$ of cargo loaded in Muuga Harbour includes crude oil and oil products, but the harbour also handles dry bulk (mostly fertilizers, grain and coal) as well as other types of 
cargo. The three oil and/or chemical terminals and one enterprise which handles ammonium nitrate, are enterprises with major chemical accident hazard potential according to the Seveso II directive (EU-directive 96/82/EC) [25] criteria (hereafter also: 'Seveso enterprises'). The two other oil terminals in the neighbourhood of the port area, also 'Seveso enterprises', use the loading equipment on the berth, which has pipeline connections with these terminals.

The Old City harbour is one of the biggest and busiest passenger harbours in the Baltic region. It is also the biggest passenger harbour for both the Port of Tallinn and all of Estonia. In 2008, the total number of passengers travelling through the Port of Tallinn was 7,247,366. Not only passengers but also trucks with dangerous goods move through the harbour. The most hazardous of these is chlorine, used by the Tallinn Water Treatment Plant.

Paljassaare Harbour is situated on Paljassaare Peninsula in Tallinn. It is a cargo port which primarily specialises in handling mixed cargo, coal and oil products, as well as timber and perishables. Two of the operators have 'Seveso enterprises': one handles oil products and another ammonium nitrate.

Paldiski South Harbour is located $45 \mathrm{~km}$ west of Tallinn. The emphasis is placed on ro-ro activity, export of local goods and transit of liquid bulk and metals. One terminal, which handles oil, chemicals and LPG and is a 'Seveso enterprise', is situated in the neighbourhood and has its loading equipment on one of the berths, connected by pipelines with the terminal.

Saaremaa Harbour is a new passenger harbour on Saaremaa, the largest island of Estonia. The harbour has 2 quays available for cruise vessels accompanied by a quay for auxiliary vessels and a floating berth for small crafts. The only considerable chemicals handling operation is the occasional bunkering of the ships.

\subsection{Analysis and improvement of emergency preparedness and response in the Port of Tallinn}

\subsubsection{Port safety in general}

The analysis of the safety control and management systems was the first step of our study and development work. This analysis included an assessment of the conformity to Estonian legislation of the management and control systems for hazard prevention and response and of the sufficiency of the mentioned systems for preventing and responding to hazards. The analysis brought out a number of problems that need additional attention and made specific proposals for their resolution.

The ISO 14001 standard has special subdivision, concerning legal and other requirements. The implementation of ISO-based IMS presumes conformance with these requirements. Thus our study turned special attention to this matter. The ports are, at the same time, dry land and maritime structures. Therefore the legislative requirements, concerning port safety exist in several international and national legal acts. There are no strict requirements, obliging the ports to create a consistent emergency management system (or approach). Thus we observed only selected legal acts, which were more directly connected with emergency preparedness and response theme. The conformity with the following acts was 
examined: The Ports Act [26], the Emergency Preparedness Act [10], the Rescue Act [27], The Chemicals Act [28] and the Occupational Health and Safety Act [29].

The Ports Act enacts a port authority as one who possesses a port and organises the activities of the port as a whole. Originating from this definition the port authority is not univocal in the landlord-type ports like the Port of Tallinn. This can give birth to contradictory interpretations and indeterminable responsibilities, e.g. no one answers for the safety in general on port areas and water areas on ports, which means there is dispersed responsibility. We consider that the best solution here could be for developing cooperation and the specification of the duties of the parties. For instance, in the sites where previously mentioned isolated oil terminals have loading equipment on the berths located on main port area and other places, the liabilities in the case of emergency are the most entangled.

The Ports Act is also the legal basis of port rules in the Estonian context. The Port Rules of the Port of Tallinn insist that companies operating in the port ensure tidiness, order and fulfill due diligence of fire precaution, environmental and health protection requirements on the territory, at the quays, in the buildings and facilities used by them. The rules require the immediate reporting of all accidents, either with people and/or equipment, pollution of the port territory, damage to vessels, quays and fenders to the Harbour Master's Office. The rules also require that the operators provide the port owner with the requisites of the person responsible for the safe handling of dangerous cargo, which seemed to function according to expectations. The rules oblige the operators of oil terminals to develop organizational and technical measures, which ensure the safety of workers, prevention of fire and sea pollution and localization and liquidation of their aftereffects, to be developed in the terminal. This is, in part, the intersection with the requirements of Seveso II directive, Chemicals Act and also ISO-based EMS or IMS for the operators, who have implemented these systems.

\subsubsection{Emergency preparedness}

The Emergency Preparedness Act provides the legal basis for the organisation of emergency preparedness of, and for, crisis management by the Government of the Republic, government agencies and local governments. The act requires the preparation of emergency plans of the enterprises pursuant to the Chemicals Act. For this reason the port operators, relevant to Seveso II Directive and some others are subjects of this obligation. The Emergency Preparedness Act simultaneously determines that, on the basis of risk assessments of rural municipalities and cities, the rural municipality and city governments shall designate the enterprises and agencies, which additionally shall prepare emergency plans. Although the municipalities have assessed the risks of responding port areas, not one municipality has posed in its risk assessment report the requirement to the port(s) to compile the emergency plan(s). Therefore the Port of Tallinn has no obligation to follow the provisions of the act, concerning the enterprises and thus its systematic approach to emergency 
preparedness and response is essentially based only on voluntary obligation in the framework of IMS, emanating from ISO 14001.

The previous version of the emergency preparedness and response procedure (hereafter also: 'procedure') was in the centre of our attention during the analysis. The 'procedure' generically conformed to the essential requirements of the ISO 14001. The detected problems concerned basically the identification of emergencies and the distribution of actions and responsibilities.

The identification of emergencies was carried out by groups of competent port employees. The lists of emergencies were composed qualitatively, relying on experiences and expert decisions - independently of the assessment of environmental aspects and other similar procedures. The participants were certainly aware of the environmental aspects assessment, as well as of the risk assessments of the operators of 'Seveso enterprises' on the port areas, the municipalities etc., but the outcomes of these were only indirectly taken into account. During the detail study of the problem, we discovered several paradoxical moments. The assessed (indirect) environmental aspects (of the terminals) were fire and releases of hazardous chemicals, but as a matter of fact the assessment methodology in use classified these as non-significant. This could be an explanation as to why we did not find the relevant environmental objectives and targets in the programmes of IMS. The 'procedure' enacted the duty of coordinating the risk assessments of the operators, handling dangerous goods, to the safety personnel of the ports. Actually the safety personnel did not even have copies of the risk assessment outcomes or safety reports. Further, it became evident that one security company, a partner of the Port of Tallinn, had conducted the general emergency risk assessment, but the outcomes were somehow forgotten or neglected by the interested parties. Therefore we recommended the composition of a systematic overview of the existing outcomes of different risk assessments and further application of additional assessment methodologies for accident and emergency risks as well as for riskrelated environmental aspects and impacts. The risks of accidents were also considered in the occupational risk assessments, which will be discussed further.

The actions and responsibilities were determined rather impersonally in the 'procedure'. Thus we recommended the further specification of the duties and responsibilities during the composition of new versions of the procedure. The specification was carried out by the departments and divisions.

Emergency plans were existing for all the five ports, deriving from the 'procedure'. As the risk assessment was a weak point in emergency preparedness, the information about the emergencies and hazard zones was rather cursory. The plans contained the response resources but not the guidance as to how to use them. The instructions for action, in several cases, comprised only the emergency communication and references to the emergency plans of the operators. Therefore we once more recommend giving more attention to the opportunities of identification of the potential accidents and emergencies. Secondly we proposed the precision of the concrete emergency actions and exploitation of relevant resources. 
The port rules included a requirement, by which all companies operating on port territory shall prepare a plan of activities for the protection of people and assets in case of fire, natural disaster, catastrophe, accident, explosion, etc. The copy of the plan of activities shall be submitted to the port owner. Operators with 'Seveso enterprises' and some others had submitted such plans, but most of the small operators had not. We supposed that every small company with almost no hazardous activities had no urgent need for their own separate emergency plan. Therefore our recommendation was the elaboration of the circle of operators, from whom the existence of the plan was reasoned in the first place.

The 'procedure' also determined the main principles of counter-pollution. The analysis ascertained that the water areas of the ports were well covered with responding measures. Each port had its marine counter-pollution plan, which realization chances were covered with competence and resources. The marine counter-pollution plans were the functional appendices of the emergency plans of the ports. Concurrently it was discovered that the counter pollution of the port (dry land) areas was set as an objective, but simultaneously without coverage. Because of this we proposed the determination of resources, operations and responsibilities for the dry land accidental pollution cases and composition of dry land counter-pollution plans for each port as appendixes to the ports (general) emergency plans.

\subsubsection{Fire safety}

The previously mentioned Rescue Act [27], among other things, enacts the organisational and construction fire safety requirements. In accordance with the act the port has delegated the performance of the fire safety requirements mainly to the operators and tenants who possess a great part of the ports areas and buildings.

In spite of the formal delegation of the full responsibility for fire safety to the operators, the real liabilities were actually distributed between the port and the operator(s), but the details were not comprehensibly fixed in the contracts. Therefore we recommended the further specification of the roles of the parties. We also suggested the improvement of general fire safety guidance and the compilation of special guidance manuals for the maintenance of fire safety installations and fire fighting water supply systems.

\subsubsection{Occupational safety - accident hazard in working environment}

Occupational safety as a whole was not the subject of our study, as the Port of Tallinn had not implemented and integrated to IMS their system of occupational health and safety management by OHSAS 18001 [30] or some other standard. Regardless, the Estonian Act of Occupational Health and Safety [29] contains the requirements for the employers in the case of emergencies and this is the only law, which claims carrying out of risk assessments (of working environment) in almost every organisation. Therefore it was decided to observe this subject in a more specific context.

Further review of the occupational risk assessment reports brought out a number of contradictions concerning the accident risks. Subsequently some examples are presented: 
1) fire risk was not assessed in certain groups of workers, but the preventive measures were described;

2) chemical accident risks were not identified and assessed for another group of port workers, who are regularly in touch with dangerous chemicals (of the operators);

3) fire risk was assessed for the office but not for the groundwood plant.

We considered the need for checking over the outcomes of the risk assessment of the working environment, concerning serious accidents and in principle proposed the further actuation of these as one source in the identification framework of the potential accidents and emergencies.

\subsection{Compilation of a handbook}

Combining experiences and observations with advice of different port specialists, a dual meaning was attributed to the handbook of emergency preparedness and response: the narrower and the broader. The handbook was composed in three parts:. The first part being a handbook in the direct sense - a guidance manual of emergency preparedness and response for persons, involved with the application and continual improvement of IMS. This part (the guidance manual) gave an overview of the risk factors occurring in the ports and of the possible hazards associated with these. The second part was the directory of safety and emergency preparedness documents, concerning specific ports, persons and events. This part, which included safety documents, was designed primarily for those port employees who were responsible for hazard prevention and response. The third part of the handbook contained plans (instructions) related to hazard prevention and response. The general starting point was the corresponding chapter of the handbook of IMS of the Port of Tallinn and the basic document of the existing procedure of emergency preparedness and response.

The first part of the handbook contained six chapters. The first and the second chapter were respectively the introduction and the scope. The third chapter included an overview of four types of hazards, which can develop into emergencies. These were: accidents with dangerous substances, pollution of the port area with oil products or other dangerous substances, fires, and bomb risks. The fourth chapter handled the general principles of safety management and guidelines for hazard response. The fifth chapter presented a review of safety assurance in the ports.

\section{Conclusion}

The study generally brought out that the integration of emergency preparedness and response to the IMS was evidently the optimal consistent solution for assuring the continuous development and improvement of that field in the Port of Tallinn.

The results of the analysis demonstrated a foreseeable need for turning attention to the following important moments in the field of emergency preparedness and response. Firstly, the improvement of the identification 
methodology of potential accidents and emergencies, secondly, the specification of the responsibilities of the departments, divisions and staff in chief of the Port of Tallinn, and thirdly, the better cooperation between the port administration, operators and municipalities.

The experiences of the study were taken into account for the compilation of the new version of the emergency preparedness and response procedure and handbook, which practically denoted the renovation and improvement of that specific part of the IMS of the Port of Tallinn. Finally we supposed that our observations and proposed solutions could serve as comparative examples for others, who were engaged with the safety and emergency problems as well as with ISO-based management systems.

\section{Acknowledgements}

This study was additionally supported by the Target Funding Project No. 1090050s07 of the Ministry of Education and Science, Estonia. The authors would like to thank the personnel of the Port of Tallinn for their cooperation and Evelin Uiga from Risk Management OÜ company for help with the expert advise.

\section{References}

[1] Flynn, A. M. \& Theodore, L., Health, safety and accident management in the chemical process industries, CRC Press, 2001.

[2] ISO 14001:2004. Environmental management systems. Specification with guidance for use, 2004.

[3] Brouwer, M.A.C. \& Koppen, C.S.A. (Kris) van, The soul of the machine: continual improvement in ISO 14001. Journal of Cleaner Production, 16, 450-457, 2008.

[4] Estonian Association for Quality, http://www.eaq.ee

[5] Port of Tallinn Handbook, http:/www.ts.ee/?k=3\&sc=195\&up=170\&t $=$ handbook

[6] Ahsen, A. von \& Funck, D. Integrated Management Systems Opportunities and Risks for Corporate Environmental Protection. Corporate Environmental Strategy, 8(2), pp. 165-176, 2001.

[7] DaGoB, http://info.tse.fi/dagob

[8] Kwon, D-M., Seo, M-S. \& Seo, Y-C., A study of compliance with environmental regulations of ISO 14001 certified companies in Korea. Journal of Environmental Management, 65, pp. 347-353, 2002.

[9] Belmane I., C. Dalhammar, \& H. Moora, Keskkonnajuhtimissüsteemi käsiraamat [Handbook of Environmental Management System] , SEITallinn, IIIEE, Lund University: Lund, 2002.

[10] The Parliament of Estonia. Emergency Preparedness Act. State Gazette I, 95, 613, 2000.

[11] Smith, K., Environmental Hazards: assessing risk and reducing disaster, Routledge: London \& New York, 2001. 
[12] 2007/162/EC, Euratom: Council Decision of 5 March 2007 establishing a Civil Protection Financial Instrument (Text with EEA relevance). http://eurlex.europa.eu/LexUriServ/LexUriServ.do?uri=CELEX:32007D01 62:EN:NOT

[13] Martin, R., ISO 14001 Guidance Manual, National Center for Environmental Decision-making Research, Technical Report NCEDR/9806, 1998. http://www.usistf.org/download/ISMS_Downloads/ISO14001.pdf

[14] Jones, S. A. \& Mason, T. W., Role of impact assessment for strategic environmental management at the firm level. Impact Assessment and Project Appraisal, 20(4), pp. 279-285, 2002.

[15] Martin, J. G. \& Edgley, G. J., Environmental Management Systems: A Guide for Planning, Development, and Implementation, Government Institutes: Rockville, 1998.

[16] Voorhees, J. \& Woellner, R. A., International Environmental Risk Management: ISO 14000 and the Systems Approach, CRC Press, 1998.

[17] Põder, T. Evaluation of Environmental Aspects Significance in ISO 14001. Environmental Management, 37(5), pp 732-743, 2006.

[18] Schaarsmith, J. H., Implementing the ISO 14001 Environmental Management System Specification, version 2.0, 2005. http://www.uml.edu /emsc/isoguide.pdf

[19] ISO 14004. 2004. Environmental management systems. General guidelines on principles, systems and supporting techniques, 2nd ed.

[20] Batts, G., An Essential Guide to ISO 14001. Chandos: Oxford, 1999.

[21] Whitelaw, K., ISO 14001 environmental systems handbook. 2nd ed., Elsevier: Oxford, 2004.

[22] Port of Tallinn, www.portoftallinn.com

[23] Port of Tallinn. Consolidated Annual Report for 2008 (Translation of the Estonian Original). http://www.portoftallinn.ee/docs/investorilt/ majandusaasta_aruanded/eng/2008_-_Annual_Report.pdf

[24] Ojala, L., Nummila, S., Suominen, M., Solakivi, T. \& Raitio, J., Safe and Reliable Transport Chains of Dangerous Goodsin the Baltic Sea Region. DaGoB publication series 6:2007. http://info.tse.fi/dagob/documents/ summaryreport/summary_report_final_pages_screen.pdf

[25] Council directive $96 / 82 / \bar{E} C$ of 9 December 1996 on the control of majoraccident hazards involving dangerous substances, OJ No L 10 of 14 January 1997 (Seveso II-Directive), and Directive 2003/105/EC of the European Parliament and of the Council of 16 December 2003 amending Council directive 96/82/EC, OJ of 31 December 2003.

[26] The Parliament of Estonia. The Ports Act, State Gazette I, 77, 1315, 1997.

[27] The Parliament of Estonia. The Rescue Act, State Gazette I, 28, 424, 1994.

[28] The Parliament of Estonia. Chemicals Act, State Gazette I, 47, 697, 1998.

[29] The Parliament of Estonia. Occupational Health and Safety Act, State Gazette I, 60, 6161999.

[30] BS OHSAS 18001:2007 Occupational health and safety management systems. Requirements. 